\title{
A COLLECTION OF
}

ABSTRACTS OF RECENT DOCTORAL RESEARCH ON THE BAHAMAS

Compiled by

Berthamae Walker, M.L.S.

Deputy Director,

Library and Instructional Media Services

https://doi.org/10.15362/ijbs.v12i0.55 


PERCEIVED SOCIAL SUPPORT AND ADULT
ATTACHMET STYLES: RELATIONSHIP WITH VIEW OF
SELF, VIEW OF OTHERS AND
HELPING TENDENCIES
Ava D. Thompson
Wayne State University
Detroit, Michigan
May, 1999
Two studies examined the generalizability of attachment - based findings on
perceived social support and adult attachment styles by comparing their rela-
tive ability to predict self-esteem, view of others and helping variables in
Bahamian samples. In study 1, the derivation of attachment styles and the
links between perceived support and attachment style and self-esteem and
retrospective accounts of early relationships with parents provided support
for the cross-cultural validity of these constructs. However, neither perceived
support nor attachment style was related to view of others as trusthworthy,
levels of cynicism and attitudes toward persons with psychological disorders
or AIDS victims. For the most part, significant findings were replicated in
Study 2. Study 2 also used a vignette design to more directly assess helping
attitudes and behaviors. Both perceived support and attachment style were
related to likelihood of being burdened by helping persons depicted in
vignettes and high perceived support individuals viewed interpersonal help as
likely to be more effective than medical support. For each of their shared vari-
ables, with the exception of likelihood of being burdened, the unique variance
of perceived support was greater than that of adult attachment style. The
results are discussed in terms of the limited predictive sphere of perceived
support and attachment style, the importance of contextualizing the helping
situation and possible directions of future research on these issues.




\section{HOLLYWOOD FILMS, REFLECTIVE PRACTICE AND \\ SOCIAL CHANGE IN TEACHER EDUCATION: A \\ BAHAMIAN ILLUSTRATION}

Faith J. Butler, Ph.D.

McGill University, 2000

This qualitative inquiry explores the use of Hollywood films depicting teachers (teacher-films) as an approach to reflective practice and social change with 60 undergraduate students in a teacher education programme in The Bahamas. In order to facilitate critical reflection on the pre-service teachers' perceptions of teaching, on themselves as teachers, and on their teaching experience, a module comprised of five teacher-films (To Sir With Love, Blackboard Jungle, Stand and Deliver, The Prime of Miss Jean Brodie, and SARAFINA!) is designed and employed. The depictions of teaching are deconstructed as a means of introducing the complexity of teaching as well as unveiling the relevance of the life of a teacher. Central to the study is exploring how prospective teachers "read" these films and what insights prospective teachers gain from the films.

The study generates four main data sources: 1) transcriptions of audiotaped group discussions with the pre-service teachers, 2) the pre-service teachers' written responses to questionnaires relating to the teacher-films, 3) reflective journals kept by the pre-service teachers, and 4) the pre-service teachers' written responses to the entire teacher-film module. The analysis of the data is presented in two parts. First, the pre-service teachers' overall response to the teacher-film module is detailed. Next, their close reading of teaching and learning as portrayed in two of the films, The Prime of Miss Jean Brodie and SARAFINA!, is discussed. A number of themes that emerge within the data such as the role, influence, and power of teachers are explored.

This inquiry has revealed how teacher-films can be utilized within teacher education to prompt neophyte teachers to examine their identity as teachers, to scrutinize their perceptions and assumptions, as well as to stimulate questions with regard to the perplexities of teaching. Film pedagogy also has potential to heighten awareness of vital issues of teaching such as race, class, and gender, to provoke self-study, and prompt social change. In addition, educators and researchers can learn much by examining pre-service teachers' responses to popular screen images of teachers as well as other popular culture images of teachers. This information can be used to design teacher education curricula that more adequately prepare neophyte teachers for the challenges of teaching. 


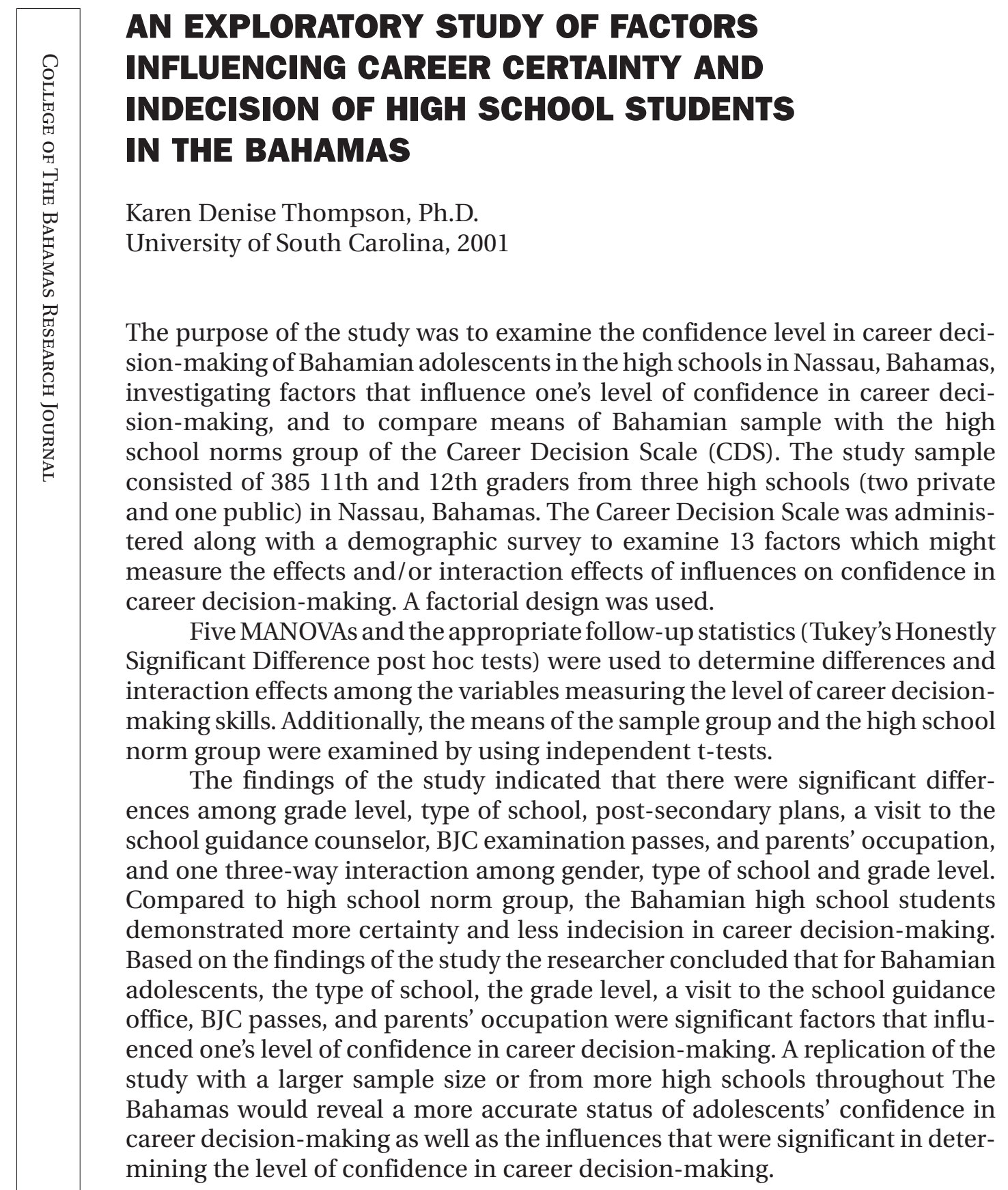




\section{PREDICATE MARKING IN THE BAHAMIAN BASILECT: AN INTEGRATED APPROACH}

Helean Arlesa McPhee, Ph.D.

University of the West Indies, 2002

This thesis examines predicate marking in Bahamian Creole data, paying particular attention to Tense, Aspect and Modal Markers, using an integrated approach. The integrated approach assumes interaction between semantics, discourse and syntax, yet insists on maintaining clear distinctions between these levels in linguistic analysis. It also assumes that semantics is basic in linguistic analysis. The integrated approach produces results which indicate a general lack of correspondence between the levels of semantics, syntax and discourse. For example, the semantic Modal go is treated by speakers as a syntactic predicator, and a Tense marker at the level of discourse. Similarly, a lack of correspondence was found with the semantic Tense marker bin and the semantic Aspect marker don and the semantic Modals hafta, gata, kyan, kud, na and iyng. Given these observations, a simple Tense-Aspect order is proposed for pre-predicate markers at the level of syntax. Nevertheless, the question is raised as to whether syntactic pre-predicate markers co-occur at all in Bahamian. In addition, the thesis measures the adequacy of its description against data cited in competing descriptions of related varieties such as Guyanese and Jamaican. Descriptions proposed for these languages are also assessed on the basis of their ability to successfully account for the Bahamian data. The tentative conclusion is that the description proposed for Bahamian is more successful in accounting for data across the various varieties than is any competing description. 


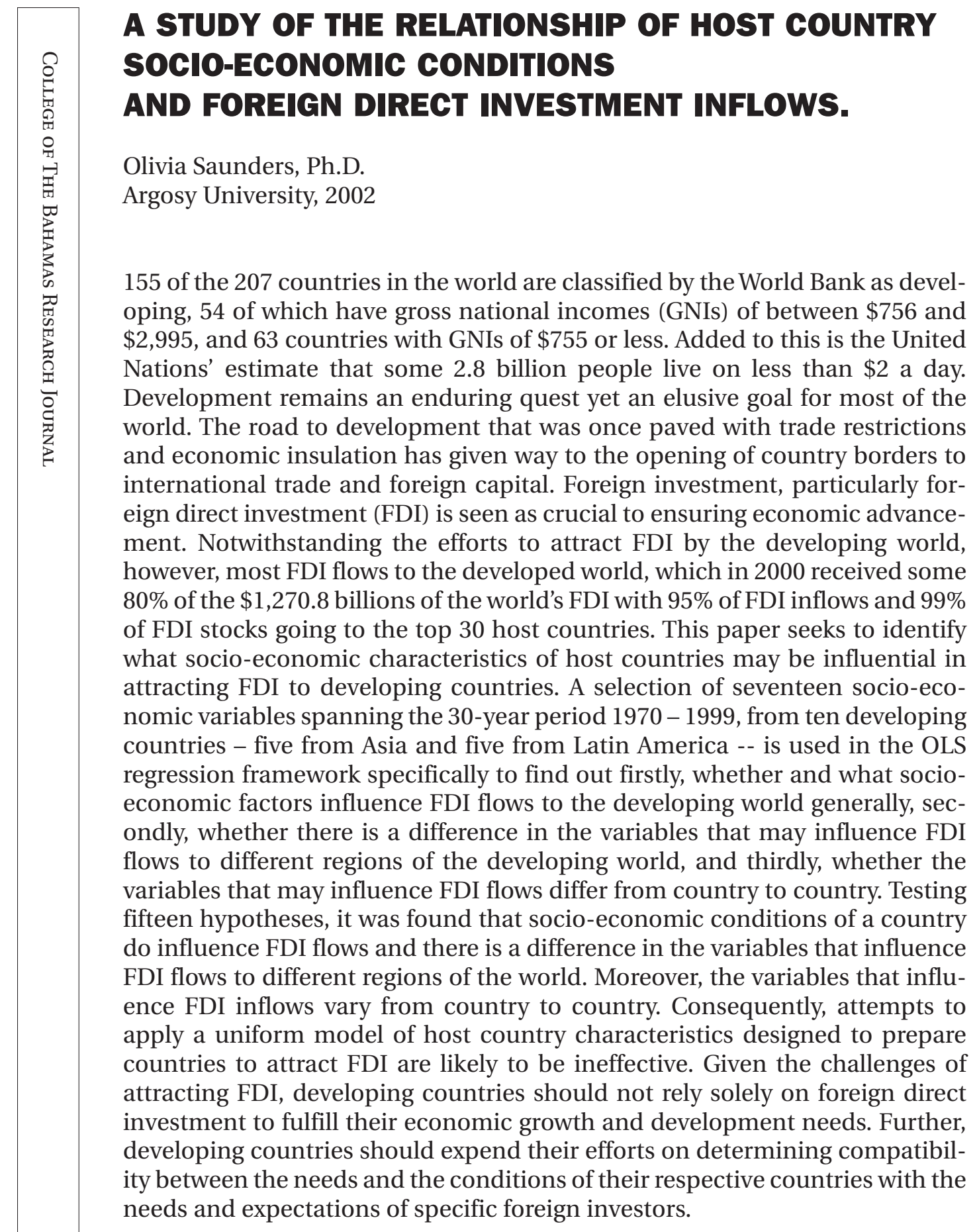




\title{
FINANCIAL RESOURCE ALLOCATION \\ DECISION-MAKING IN PUBLIC HIGHER \\ EDCATION IN THE COMMOMWEALTH OF THE \\ BAHAMAS: A COLLECTIVE CASE STUDY.
}

\author{
Adrilla Horton-Wallace, Ph.D. \\ Kent State University, 2002
}

The purpose of this study was to determine the strategies utilized in the financial resource allocation process in public higher education in The Commonwealth of The Bahamas. Specifically, current budgetary strategies used at the state and institutional levels were examined to identify agreement or disagreement between the two levels and to determine the decision-making model.

The literature on budget allocation identified several budgeting approaches to financial resource allocation decision-making in higher education. These methods could be classified under two major models: the politically rational and objectively rational budgeting models. Merson and Qualls (1979) suggested decisions related to allocations of resources in a college or university were among the most important decisions of administrators and governing boards. To make these decisions responsibly, a well-articulated process of resource allocation is needed. For Sizer (1982), this process is a rational one, as it must be consistent with the university's development plan and mission.

Rational decision-making, like most present-day problem-solving approaches, has its base in Dewey's (1910) analysis of reflective thought. This analysis identified five logically distinct steps involved in reflection: the occurrence of a difficulty (identifying a problem), its location and definition (determining its nature), suggestion of a possible solution, analysis of the suggestions, further observation and experiment leading to its acceptance or rejection. But the rationality in this process is only a conceptual attempt to exclude individual views or experiences in decision-making. In keeping with this underlying belief in an individual's ability to act in isolation of personal experiences, several other scholars developed and defined Dewey's analysis.

This study was designed to determine the budgetary strategies used in public higher education in The Commonwealth of The Bahamas, and the decision-making model underlying the process. The results showed a politically rational decision-making model at work throughout public budgeting and within higher education institutions, with minimal consideration given to objective analysis. Incremental line item budgeting resulted in financial constraints for institutions and created frustration between state and institutions; yet little effort seemed to be directed at alternative, non-government sources of funding. However, the need for alternative sources of funding was expressed throughout the study. There was a general call for efficiency from state administrators; accountability was assured through the expenditure reporting mechanisms contained in the budget. Also no strategic connection between allocations and plans and no clarity in the role that higher education can and should play in galvanizing the nation forward was evident. These findings also supported findings of Smith (1995) and Williams (1999) about the efficacy of political and rational decision-making in resource allocation in higher education institutions. 